\title{
КЛАССИФИКАЦИЯ И ТЕНДЕНЦИИ РАЗВИТИЯ МЕЖДУНАРОДНЫХ ДОКУМЕНТОВ В СФЕРЕ ОБЕСПЕЧЕНИЯ И ЗАЩИТЫ ПРАВ ЖЕНЩИН
}

\author{
Фируза Хамдамова, стариий преподаватель, соискатель, \\ Университет мировой экономики и дипломатии, Узбекистан
}

DOI: https://doi.org/10.31435/rsglobal_ws/31082019/6628

\section{ARTICLE INFO}

Received: 20 June 2019

Accepted: 15 August 2019

Published: 31 August 2019

\section{KEYWORDS}

women's rights, multiple discrimination, protection from violence, maternity protection, convention, reservations, cultural relativism.

ABSTRACT

The article is devoted to the classification of international documents in the field of ensuring and protecting the rights of women. The author systematizes them for several reasons, namely: depending on the subject who accepted the document, according to its legal nature, on the range of issues regulated by the document, its geographical scope. The author also raises the question of the reasons for the ineffectiveness of some documents on women's rights, in particular, the issue of reservations and cultural relativism.

Thus, today there is a huge array of international documents on the rights of women, which are a fairly solid legal basis for effectively ensuring the rights of women. These documents are adopted in various forms - in the form of declarations, recommendations, conventions and programs or strategies of actions, that is, in the form of documents of a mandatory or recommendatory nature. An analysis of their content made it possible to highlight the most priority areas of international legal cooperation in the field of ensuring the rights of women, namely, maternity protection, ensuring equality in the family and the world of work, and protecting women from violence. More and more documents are being adopted in order to protect vulnerable layers of women facing multiple discrimination. The adoption of documents on the protection of the most vulnerable categories of women, that is, women exposed to multiple discrimination, is one of the trends in the development of international legal standards on women's rights.
\end{abstract}

Citation: Фируза Хамдамова. (2019) Klassifikaciya i Tendencii Razvitiya Mezhdunarodnyh Dokumentov v Sfere Obespecheniya i Zashchity Prav Zhenshchin. World Science. 8(48), Vol.1. doi: 10.31435/rsglobal_ws/31082019/6628

Copyright: (C) 2019 Фируза Хамдамова. This is an open-access article distributed under the terms of the Creative Commons Attribution License (CC BY). The use, distribution or reproduction in other forums is permitted, provided the original author(s) or licensor are credited and that the original publication in this journal is cited, in accordance with accepted academic practice. No use, distribution or reproduction is permitted which does not comply with these terms.

Со второй половины XX века и по настоящее время, в международном праве увеличивается удельный вес норм, направленных на правовую защиту положения женщин в мире. На сегодняшний день действует огромный массив международных документов по правам женщин, представляющих собой достаточно солидную правовую основу для обеспечения прав женщин. Эти документы приняты в различных формах - в форме деклараций, рекомендаций, конвенций и программ или стратегий действий, то есть в форме документов обязательного или рекомендательного характера.

Наряду с общими международными документами по правам человека, т.е. применимыми в равной мере ко всем, в отдельную группу можно выделить специальные документы, посвященные только правам женщин.

В свою очередь, специальные документы, касающиеся только прав женщин, можно подразделить на документы универсального и регионального характера. Следует отметить, что Узбекистан участвует в большей степени именно в универсальных документах (а именно в документах, принятых в рамках $\mathrm{OOH})$, нежели в региональных. 
Универсальных документов по правам женщин, принятых в рамках ООН, принято огромное количество, что обуславливает необходимость их классификации. В частности, универсальные специальные документы, касающиеся только женщин, можно классифицировать на следующие категории.

1) Классификация в зависимости от субъекта, принявшего документ. $\mathrm{B}$ зависимости от того, в рамках какого механизма приняты рассматриваемые нами документы, можно выделить следующие их категории:

- документы, принятые органами ООН;

- документы, принятые специализированными учреждениями $\mathrm{OOH}$;

- документы, принятые в рамках всемирных конференций по вопросам прав человека и женщин.

В свою очередь, документы, принятые органами ООН, также можно подразделить на следующие группы:

- документы, принятые главными уставными органами ООН;

- документы, принятые вспомогательными органами ООН по правам человека (Совет $\mathrm{OOH} \mathrm{по} \mathrm{правам} \mathrm{человека} \mathrm{(СПЧ} \mathrm{ООН),} \mathrm{Управление} \mathrm{Верховного} \mathrm{Комиссара} \mathrm{ООН} \mathrm{по} \mathrm{правам}$ человека (УВКПЧ);

- документы, принятые договорными органами ООН по правам человека. ${ }^{2}$

Важный вклад имеют документы, принятые специализированными учреждениями ООН, а именно МОТ, ВОЗ, ЮНЕСКО и др.

Важный вклад внесли всемирные конференции по положению женщин. На сегодняшний день проведены четыре всемирные конференции, посвященные правам женщин. Основным итогом всемирных конференции стало принятии планов действий, программ и деклараций. ${ }^{3}$

Среди них следует выделить Пекинскую декларацию и Платформу действий, который представляет собой план по реализации, защите и поощрению равных прав и возможностей для женщин и мужчин. ${ }^{4}$ О принципиальном значении итоговых документов Пекинской конференции свидетельствует систематическая ссылка на них в резолюциях ГА, ЭКОСОС и Совета Безопасности ООН. ${ }^{5}$ Кроме того, ГА своей резолюцией 50/203 рекомендовала

1 Касательно документов, принятых главными органами ООН, в качестве примера можно привести Конвенцию о политических правах женщин 1953 г. или Декларацию о ликвидации дискриминации в отношении женщин 1967 г.

2 Договорные органы ООН по правам человека, например, Комитет ООН по ликвидации дискриминации в отношении женщин, принимают документы в виде общих рекомендаций и заключительных замечаний по итогам рассмотрения периодических докладов государств.

${ }^{3}$ Первая всемирная конференция по положению женщин была созвана в Мехико в 1975г. Ее результатом стало объявление периода 1976-1985 годов Десятилетием женщины ООН и учреждение Фонда добровольных взносов для Десятилетия. Вторая всемирная конференция по положению женщин созвана в Копенгагене в 1980г. для анализа и оценки выполнения Всемирного плана действий 1975г. Ее результатом стало принятие Копенгагенской Программы действий. Третья Всемирная конференция по положению женщин (Найроби, Кения) в 1985г., по итогам которой были приняты Найробийские перспективные стратегии в области улучшения положения женщин на период до 2000г. Кроме того, результатом работы Конференции в Найроби также было преобразование Фонда добровольных взносов для Десятилетия женшины ООН в Фонд ООН для развития в интересах женщин (ЮНИФЕМ). Между третьей и четвертой всемирными конференциями женщин было принято два важных международных документа, направленных на достижение гендерного равенства. Это Венская декларация и Программа действий, принятые Всемирной конференцией по правам человека, которая состоялась в столице Австрии в 1993г. На Венской конференции по правам человека было закреплено, что «права человека женщин и девочек являются неотъемлемой составной и неделимой частью всеобщих прав человека». Четвертая Всемирная Конференция по положению женщин, которая прошла в Пекине в 1995г., подвела итоги, выполнения Найробийских стратегий по изменению положения женщин и утвердила Пекинскую декларацию и Пекинскую Платформу действий.

${ }^{4}$ В данном документе выделено 12 важнейших проблемных областей, где женщины в наибольшей степени подвержены дискриминации: женщины и нищета; образование и профессиональная подготовка женщин; женщины и здравоохранение; насилие в отношении женщин; женщины в период вооруженных конфликтов; женщины и экономика; участие женщин в работе директивных органов и в процессе принятия решений; институциональные механизмы улучшения положения женщин; женщины и права человека; женщины и средства массовой информации; женщины и окружающая среда; девочки

${ }^{5}$ К примеру, ГА ООН каждый год рассматривает и принимает резолюции о последующей деятельности в связи c IV Всемирной конференцией по положению женщин и о полном осуществлении Пекинской декларации и Платформы действий, в которых признает, что данный документ и Конвенция 1979 г. подкрепляют друг друга в 
государствам - участникам Конвенции о ликвидации всех форм дискриминации в отношении женщин (КЛДОЖ) включать в свои доклады (согласно ст. 18 Конвенции) информацию о мерах, принимаемых для осуществления мероприятий, предусмотренных Пекинской платформой действий. В-пятых, большинство положений Пекинской платформы обязательны для исполнения в силу их закрепления в Конвенции о ликвидации всех форм дискриминации в отношении женщин 1979 г. По сути, принятие Платформы действий было призвано усилить и конкретизировать положения названной Конвенции, разработать действенный план по их практической реализации на международном, региональном и национальном уровнях. ${ }^{1}$

Это обуславливает и подтверждает высокую практическую значимость данного документа. ${ }^{2}$

2) Классификация в зависимости от круга вопросов и содержанию документов.

Исходя из анализа содержания рассматриваемых документов, можно выделить следующие категории:

A) документы касательно охраны материнства;

Б) документы касательно прав женщин в семейно-брачных отночениях;

В) документы касательно прав женшиин в сфере труда;

Г) документы касательно зашиты женшин от насилия;

Д) документы касательно уязвимых категорий женщиин (например, беженки, пожилье женщины и т.д.).

Касательно документов по охране материнства, международно-правовая защита материнства и детства находит свое отражение в основополагающих документах о правах человека уже с начала XX столетия, а именно во Всеобщей декларации прав человека, ${ }^{3}$ Международном пакте об экономических, социальных и культурных правах ${ }^{4}$, Конвенции о ликвидации всех форм дискриминации в отношении женщин ${ }^{5}$, Конвенции о правах ребенка. ${ }^{6}$ Особое место в системе документов по охране материнства Конвенции и рекомендации МOT. ${ }^{7}$ Можно отметить три конвенции МОТ об охране материнства (№ 3, 1919; №103, 1952; № 183, 2000) и сопутствующие им рекомендации (№ 95, 1952; № 191, 2000). ${ }^{8}$ Особое внимание этим вопросам уделено в Пекинской

деле реализации равенства мужчин и женщин. Особое значение Пекинской декларации и Платформы действий было отмечено на 23-й специальной сессии ГА ООН «Женщины в 2000 году: равенство между мужчинами и женщинами, развитие и мир в XXI веке. Важность документов Пекинской конференции была отмечена в резолюции Совета Безопасности ООН 1325 (2000) «Женщины и мир и безопасность.

Сягровец Е.В. Роль Пекинской конференции 1995 г. и еe итоговых документов в формировании механизма реализации гендерного равенства на международном и национальном уровнях. [Эл. Ресурс] URL: http://elib.bsu.by/bitstream/123456789/92311/1/saygrovets_2013_5_IL_issues.pdf (последняя дата обращения 5 апреля 2019г.)

${ }^{2}$ Там же

${ }^{3}$ Декларация закрепила, что материнство и младенчество дают право на особое попечение и помощь (п. 2 ст. 25).

4 Статья 10 (2) пакта гласит “Особая охрана должна предоставляться матерям в течение разумного периода дои после родов. В течение этого периода работающим матерям должен предоставляться оплачиваемый отпуск или отпуск с достаточными пособиями по социальному обеспечению”.

${ }^{5}$ Статья 11 Конвенции закрепляет недопущение дискриминации в сфере занятости; безопасность труда и охрана здоровья; запрет на увольнение во время беременности и отпуска по беременности и родам; оплачиваемый отпуск по беременности и родам; меры, дающие возможность женщинам сочетать семейные обязанности и трудовую деятельность (службы по уходу за детьми); защита от вредных для здоровья видов работ во время беременности. Статья 12.2 Конвенции закрепляет обязанность государств-участников обеспечивать женщинам соответствующее обслуживание в период беременности, родов и послеродовой период, предоставляя, когда это необходимо, бесплатные услуги.

${ }^{6}$ Статья 18(2) Конвенции гласит, что в целях гарантии и содействия осуществлению прав, изложенных в настоящей Конвенции, государства-участники оказывают родителям и законным опекунам надлежащую помощь в выполнении ими своих обязанностей по воспитанию детей и обеспечивают развитие сети детских учреждений. Статья 18(3) предусматривает, что государства-участники принимают все необходимые меры для обеспечения того, чтобы дети, родители которых работают, имели право пользоваться предназначенными для них службами и учреждениями по уходу за детьми.

${ }^{7}$ Полный текст конвенций и рекомендаций MOT находится в ILOLEX (Базе данных MOT по трудовым нормам) http://www.ilo.org/ilolex/index.htm

${ }^{8}$ Кроме того, вопросы охраны материнства затронуты в резолюциях Международной конференции труда (МКТ). В 1985г. МКТ приняла Резолюцию о равенстве возможностей и обращения для мужчин и женщин в сфере занятости. В 2004 году МКТ приняла Резолюцию о гендерном равенстве, справедливой оплате труда и охране материнства, а в 2009г. - Резолюцию о гендерном равенстве - как основе достойного труда. 
платформе действий 1995г., которая призывает к обеспечению охраны материнства и сбалансированному распределению рабочих и семейных обязанностей (Параграфы 106, 179). ${ }^{1}$

Как отмечалось выше, в отдельную группу можно выделить документы, касающиеся брачных отношений. Право на семью закреплено в Международном пакте об экономических, социальных и культурных правах 1966г. ${ }^{2}$ В 1954 г. ГА ООН приняла резолюцию, в которой рекомендовала установить брачный возраст и другие условия, необходимые для создания семьи. В 1957 г. была принята Конвенция о национальности замужних женщин, в 1962 г. Конвенция о согласии на вступление в брак, брачном возрасте и регистрации браков. ${ }^{3}$ Ряд общих положений содержатся в Конвенции 1979 г., которые получили развитие в общих рекомендациях Комитета. В частности, круг обязательств государств подробно объясняется в Общей рекомендации № 21 о равенстве в браке и семейных отношениях. ${ }^{4}$

Касательно группы документов относительно прав женщин в сфере труда и занятости, специальные меры получили отражение в Конвенции ООН о ликвидации всех форм дискриминации в отношении женщин 1979 г. ${ }^{5}$ Существует также целый ряд конвенций и рекомендаций МОТ по вопросам женского труда: Конвенция о равном вознаграждении, 1951 г. (№100) и сопутствующая Рекомендация о равном вознаграждении, 1951 г. (№90), Конвенция о дискриминации в области труда и занятий, 1958г. (№ 111), Конвенция о трудящихся с семейными обязанностями 1981г. (156) и др.

Относительно группы документов по защите женщин от насилия следует отметить, что в течение долгого времени международное право в области прав человека ничего не говорило о проблеме насилия в отношении женщин. До конца 1970-х-начала 1980-х гг. насилие в отношении женщин и насилие в семье, в частности, не рассматривались как имеющие отношение к правам человека. Проблемы бытового насилия (домашнего насилия или насилия в семье) не стали объектом регулирования Конвенции 1979 г., но были исследованы Комитетом по правам женщин в его Общей рекомендации №19. ${ }^{6}$ Важной вехой стало принятие в 1993 г. Декларации об искоренении насилия в отношении женщин. ${ }^{7}$ Важно подчеркнуть, что необязательная юридическая природа документа нисколько не умаляет ее значимости, поскольку ее принятие способствовало привлечению вниманию международной общественности к вопросам насилия в отношении

\footnotetext{
${ }^{1}$ Текст Декларации доступен на http://www.un.org/ru/documents/decl_conv/declarations/womdecl.shtml

2 Согласно статье 10 Пакта государство должно предоставлять семье по возможности самую широкую защиту и помощь, в особенности в момент ее создания и период супружеской заботы о несамостоятельных детях. Брак должен заключаться по свободному согласию вступающих в него лиц. Особая охрана должна предоставляться матерям (в течение разумного периода) до и после родов. В течение этого периода работающим матерям должен предоставляться оплачиваемый отпуск или отпуск с достаточными пособиями по социальному обеспечению.

3 Конвенция закрепила, что не допускается заключения брака без полного и свободного согласия обеих сторон, которое должно быть изъявлено им лично, в соответствии с законом, после надлежащего оглашения. Государства-участники Конвенции обязаны принять законодательные акты, устанавливающие минимальный брачный возраст. При этом не допускается заключение брака с лицом, не достигшим установленного возраста, кроме тех случаев, когда компетентный орган власти в интересах сторон, вступающих в брак, разрешает сделать из этого правила о возрасте исключение по серьезным причинам.

4 Текст Общих рекомендаций доступен на сайте УВКПЧ ООН www.ohchr.org.

5 Государства-участники должны принимать соответствующие меры для того, чтобы: • запретить под угрозой применения санкций, увольнение с работы на основании беременности и родам или дискриминацию ввиду семейного положения при увольнении; • ввести оплачиваемые отпуска или отпуска с сопоставимыми социальными пособиями по беременности и родам без утраты прежнего места работы, старшинства или социальных пособий; • поощрять предоставление необходимых дополнительных социальных услуг, с тем, чтобы позволить родителям совмещать выполнение семейных обязанностей с трудовой деятельностью и участием в общественной жизни, в частности посредством создания и расширения сети учреждений по уходу за детьми; • обеспечивать женщинам особую защиту в период беременности на тех видах работ, вредность которых для их здоровья доказана.

${ }^{6}$ Комитет определил домашнее насилие как одну из наиболее коварных форм насилия в отношении женщин и рекомендовал внедрение специального законодательства, направленного на защиту от домашнего насилия, создание защитных и поддерживающих служб для женщин, и гендерноориентированные тренинги для правоохранительных и судебных органов.

${ }^{7}$ Принята резолюцией 48/104 Генеральной Ассамблеи от 20 декабря 1993 года. Декларация дает определение понятия «домашнего насилия», предусматривает формы насилия, определяет важнейшие причины насилия в отношении женщин, а также круг самых необходимых мер для решения проблемы.
} 
женщин. Кроме того, в настоящее ряд авторов выдвигают предложение о принятии Конвенции об искоренении насилия в отношении женщин. ${ }^{1}$

Другой пример наиболее распространенной формы насилия в отношении женщин - это торговля женщинами. В отличие от домашнего насилия, против торговли людьми на сегодняшний день приняты ряд документов обязательного характера, что свидетельствует об однозначном негативном отношении международного сообщества к данному явлению (в отличие от бытового насилия). Среди наиболее важных документов можно отметить Конвенцию о ликвидации торговли людьми и эксплуатации проституции других 1950 г., и Протокол о предупреждении и пресечении торговли людьми, особенно женщинами и детьми, и наказании за нее 2000 г., дополняющем Конвенцию ООН против транснациональной организованной преступности (известном также как Палермский протокол).

Следующая группа документов по правам женщин - это документы, посвященные защите наиболее уязвимых слоев женщин. Среди них особого упоминания заслуживают международные конвенции по гуманитарному праву, а именно четыре Женевские Конвенции 1949 г. по защите жертв вооруженных конфликтов. ${ }^{2}$ В Конвенциях есть некоторые специальные нормы, направленные на защиту женщин в период вооруженных конфликтов. ${ }^{3}$ Дальнейшее развитие положения Женевских Конвенций по гуманитарному праву получили в Дополнительных Протоколах к ним 1977г. ${ }^{4}$

Особое внимание международное право уделяет женщинам-беженцам. Руководящую роль здесь играет деятельность Управления верховного комиссара ООН по делам беженцем (УВКБ). «Руководящие принципы защиты женщин-беженок», изданные УВКБ ООН в 1991г., стали важным инструментом для решения конкретных проблемах защиты, с которыми сталкиваются женщины-беженки. ${ }^{5}$

Отдельное внимание уделяется женщинам-заключенным. Так, приняты Правила ООН, касающиеся обращения с женщинами-заключенными и мер наказания для женщинправонарушителей, не связанных с лишением свободы (Бангкокские правила) 2010 г. ${ }^{6}$ и Типовые стратегии и практические меры по искоренению насилия в отношении женщин в области предупреждения преступности и уголовного правосудия 1997 г. ${ }^{7}$

К уязвимым слоям женщин также относятся пожилые женщины, женщины-инвалиды, женщины, проживающие в сельской местности, женщины-мигранты и так далее. В целом, обзор общих рекомендаций Комитета по ликвидации дискриминации в отношении женщин показывает, что последние общие рекомендации, практически все посвящены именно этим группам женщин, в частности, Общая рекомендация 18 посвящена женщинам-инвалидам, Общая рекомендация 26 женщинам -мигрантам, Общая рекомендация 30 - женщинам в зонах конфликта, Общая рекомендация 32 - женщинам-беженцам или апатридам, Общая рекомендация 34 - женщинам, проживающим в сельской местности и т.д. ${ }^{8}$ Это свидетельствует о повышении внимания к наиболее уязвимым группам женщин, то есть тех, которые нуждаются в особой помощи в связи с

\footnotetext{
${ }^{1}$ Поленина С.В. Права женщин в системе прав человека: международный и национальный аспект. М., 2000. - С.57

2 Эти Конвенции носят названия «Об улучшении участи раненых и больных в действующих армиях», «Об улучшении участи раненых, больных и лиц, потерпевших кораблекрушение, из состава вооруженных сил на море», «Об обращении с военнопленными» и «О защите гражданского населения во время войны».

${ }^{3}$ B IV Женевской Конвенции есть особые правила о защите женщин от всяких покушений на их честь, в частности от изнасилования, принуждения к проституции и непристойных посягательств. Особое внимание уделяется Женевскими Конвенциями защите беременных женщин, рожениц и матерей малолетних детей. Им предоставляются особые льготы при задержании, аресте и интернировании, им должно обеспечиваться дополнительное питание, лечение, медицинская помощь и т.д.

${ }^{4}$ Дополнительный Протокол I к Женевским конвенциям 1949г. предусматривает приравнивание рожениц и беременных женщин к больным и раненым, поскольку им в любом случае понадобиться медицинская помощь и особое обращение при транспортировке. Также можно отметить Декларацию о защите женщин и детей в чрезвычайных обстоятельствах и в период вооруженных конфликтов 1994 г.

${ }^{5}$ Кроме того, в 1999г. УВКБ приняло Стратегию учета гендерной перспективы во всех своих программах и отчетности, а в 2004г. оно приняло и начало реализацию стратегии комплексного учета возраста, гендера и многообразия (КУВГМ) в рамках всей организации.

${ }^{6}$ Приняты резолюцией 65/229 Генеральной Ассамблеи от 21 декабря 2010 года.

7 Приняты резолюцией 52/86 Генеральной Ассамблеи от 12 декабря 1997 года

8 Текст общие рекомендаций Комитета ООН по ликвидации дискриминации в отношении женщин доступен на сайте УВКПЧ ООН по ссылке https:/www.ohchr.org/EN/HRBodies/CEDAW/Pages/Recommendations.aspx
} 
тем, что становятся жертвами дискриминации по нескольким основаниям. Это так называемая «множественная дискриминация» или «перекрестная дискриминация».

Важно отметить, что вопросы защиты уязвимых категорий женщин - относительно новое направление исследований в сфере обеспечения прав женщин. Вместе с тем, большинство документов, посвященных защите таких групп, носят декларативный, необязательный характер. В этой связи, важно отметить, что в международном праве, особенно в сфере защиты прав человека, неоднократно имела место практика, когда декларативные нормы постепенно получали признание и статус юридически обязательных. Примером может служить Конвенция о ликвидации всех форм дискриминации в отношении женщин, предпосылкой для принятия которой послужила одноименная Декларация. ${ }^{2}$ Предполагается, что со временем, общие рекомендации Комитета касательно уязвимых категорий женщин будут систематизированы и приняты в форме юридического обязательно документа, например, в форме еще одного Факультативного протокола к Конвенции или отдельной Конвенции.

\section{3) Классификация в зависимости от юридической природы документа.}

Документы по правам женщин подразделяются на документы обязательного и рекомендательного характера. Обязательные документы приняты в форме конвенций, а рекомендательные - в форме деклараций, рекомендаций, программ действий и т.д.

К рекомендательным документам можно отнести, например, рекомендации МОТ, документы, принятые в рамках всемирных конференций по положению женщин, общие рекомендации Комитета по ликвидации дискриминации в отношении женщин, которые формулируются для обеспечения более глубокого понимания положений Конвенции 1979г., и для предоставления государствам-участникам руководства по обеспечению выполнения положений Конвенции. ${ }^{3}$

Отдельное внимание при этом следует уделить вопросу о юридической силе Пекинской декларации и Платформы действий. Одни ученые считают, что заключительные акты международных конференций не являются юридически обязательными, но в силу принципа добросовестности выполнения международных обязательств предполагается, что они будут уважаться участниками как морально-политические обязательства. ${ }^{4}$ По мнению Ю.М.Колосова, совместные заявления государств (по итогам переговоров, конференций) могут служить вспомогательным средством для определения обычной нормы. ${ }^{5}$ Н.А.Ушаков, не причисляя акты международных конференций к документам, обладающим юридической силой международных договоров, все же подчеркивал, что государства, подписав данное соглашение, подразумевают необходимость соблюдения его положенийб. Что касается заключительного акта Пекинской конференции - Платформы действий, ее положения являются обязательными для исполнения государствами-участниками по следующим основаниям: во- первых, заключительный акт Пекинской конференции является результатом согласования воли суверенных государств, членов $\mathrm{OOH}$, субъектов международного права; во-вторых, правила, закрепленные в этих документах, имеют общий характер и должны реализовываться во всех предусмотренных документами случаях; в-третьих, формулировки, используемые в итоговых документах Пекинской конференции, имеют форму долженствования; в-четвертых, Пекинская платформа действий предусматривает механизмы контроля за соблюдением принятых на себя обязательств. В частности, в системе ООН создан трехступенчатый межправительственный механизм контроля, который включает ГА,

\footnotetext{
${ }^{1}$ Паола Учеллари. Множественная дискриминация: как законодательство может отражать реальность// Журнал The Equal Rights Review, № 1-7 (2008-2011) - C. 11

2 Поленина С.В. Права женщин в системе прав человека: международный и национальный аспект. Москва, 2000. - С. 15.

3 На сегодняшний день издано 37 общих рекомендаций Комитета по ликвидации дискриминации в отношении женщин. Тексты общих рекомендации Комитета можно найти на сайте Организации Объединенных Наций: http://www2.ohchr.org/english/bodies/cedaw/comments.htm

${ }^{4}$ Василенко В. А. Основы теории международного права. - Киев: Вищ. шк., 1988. - С.2; Лукашук И. И. Международное право. Общая часть: учеб. для студентов юрид. фак. и вузов. - М.: Волтерс Клувер, 2007.-С.27

${ }^{5}$ Международное право: учебник / отв. ред.: Ю. М. Колосов, Э. С. Кривчикова. - 2-е изд., перераб. и доп. - М.: Междунар. отношения, 2005. - С.59

6 Ушаков Н. А. Международное право: учебник. - М.: Юристъ, 2003. - С.24
} 
ЭКОСОС и КПЖ, уполномоченные разрабатывать и координировать общую политику осуществления положений Пекинской платформы действий по улучшению положения женщин. ${ }^{1}$

Таким образом, на сегодняшний день действует огромный массив международных документов по правам женщин, представляющих собой достаточно солидную правовую основу для обеспечения прав женщин. Однако в обществе все еще сохраняются различные предрассудки и стереотипы, которые приводят к возникновению гендерного неравенства. ${ }^{2}$ Женщины продолжают сталкиваться с дискриминацией, как скрытой, так и явной.

В связи с этим, вполне правомерен вопрос о том, почему же ратифицированная, то есть признанная в качестве международного эталона Конвенция 1979г. выполняется далеко не во всем мире и какие меры следует предпринять международному сообществу, чтобы добиться ее эффективности.

Это обусловлено двумя фактами. Во-первых, многие государства, ратифицируя Конвенцию 1979г., сделали при этом большое число весьма существенных оговорок и заявлений. Оговорки существенно снижают эффективность Конвенции. ${ }^{3}$ И, во-вторых, до сих пор не начал действовать механизм подачи индивидуальных заявлений в отношении большинства государств мира большинство стран-участниц Конвенции все еще не ратифицировала Факультативный протокол к Конвенции, который предусматривает данный механизм. ${ }^{4}$

Касательно оговорок, Комитет по ликвидации дискриминации в отношении женщин выражает озабоченность в связи со значительным числом оговорок и предлагает всем заинтересованным государствам - участникам пересмотреть такие оговорки с целью их снятия ${ }^{5}$. Комитет предлагает всем государствам - участникам постепенно идти к снятию своих оговорок, в частности к статьям 9, 15 и 16 Конвенции ${ }^{6}$. На Всемирной Конференции по правам человека в 1993 г. также было отмечено, что государства должны быть более ответственными при реализации права на оговорки и регулярно рассматривать возможность их снятия (п. 26 и 5 Венской Декларации и Программы Действий).

Причиной оговорок являются культурные особенности государств-участниц. Точнее, очень часто государства пытаются оправдать нарушения прав женщин культурными особенностями. Такой подход рассматривается в рамках концепции культурного релятивизма, противопоставляемой идее универсальности прав человека. Спор между универсалистами и культурными релятивистами - одна из постоянных проблем международного права прав человека. Особенно ярко это проявляется в вопросах обеспечениях прав женщин. Сторонники универсальности прав человека предполагают наличие определенных общих стандартов прав человека, применимых к любому обществу. ${ }^{7}$ Сторонники культурного релятивизма поддерживают концепцию, согласно которой человеческие ценности носят не всеобщий характер, а существенно зависят от культурных и религиозных особенностей народа. ${ }^{8}$

Некоторые авторы выделяют деструктивный и конструктивный культурный релятивизм. Деструктивный релятивизм направлен на упразднение универсального статуса международных прав человека. Конструктивный релятивизм не отрицает универсального характера прав человека, но в процессе их реализации предлагает учитывать культурные, исторические, экономические и другие особенности конкретного общества. Учет этих

\footnotetext{
${ }^{1}$ РезолюцииГА ООН 50/203 от 22 декабря 1995 г.; 51/69 от 12 декабря 1996 г.; 52/100 от 12 декабря 1997 г.; 53/120 от 9 декабря 1998 г.; 54/141 от 17 декабря 1999 г.,

2 Торосян Р. А. Международные стандарты гендерного равенства.//Государство и право. Юридические науки. // Изв. Сарат. ун-та. Нов. сер. Сер. Экономика. Управление. Право. 2015. Т. 15, вып. 3. С. 347-? DOI: https://doi.org/10.18500/1994-2540-2015-15-3-347-352

${ }^{3}$ Бюргенталь Т. Международные права человека. Краткий обзор. Пер с англ. Алматы: Гылым, 1999. - С. 78

4 На данный момент Протокол ратифицировали около 130 государств мира. https://treaties.un.org/Pages/ViewDetails.aspx?src=TREATY\&mtdsg_no=IV-8-b\&chapter=4\&clang=en

${ }^{5}$ Общие Рекомендации Комитета ООН по ликвидации дискриминации в отношении женщин №̄/1987.

${ }^{6}$ Комитет по ликвидации дискриминации в отношении женщин. Общая рекомендация № 28, касающаяся основных обязательств государств-участников по статье 2 Конвенции о ликвидации всех форм дискриминации в отношении женщин. CEDAW/C/GC/28

7 Шафиев К. Универсальность прав человека и принцип культурного релятивизма//Кавказ и глобализация. том 2. выпуск 1. 2008. - С.116

${ }^{8}$ Там же
} 
особенностей необходим, так как позволяет выявить наиболее эффективные способы внедрения и защиты международных стандартов прав человека. ${ }^{1}$

Более того, Марк Кильсгард, полагает, глобальной тенденцией в области прав человека является переход от культурного релятивизма к концепции универсализма. Эту тенденцию он называет необратимой и связывает ее с рядом факторов: 1) ростом благосостояния народов (чем больше нация процветает, тем больше она проявляет интереса к правам человека; 2) глобализацией (этот процесс стирает культурные различия между народами и выдвигает на первое место их схожие черты); 3) отступлением от прежних позиций в отношении государственного суверенитета и правового позитивизма, что подтверждается влиянием международных организаций и возросшей ответственностью за несоблюдение норм международного права. Эти факторы лишают релятивизм прежней философской подоплеки. ${ }^{2}$

В этой связи, Конвенция о ликвидации всех форм дискриминации в отношении женщин предписывает государствам «изменить социальные и культурные модели поведения мужчин и женщин с целью достижения искоренения предрассудков и упразднения обычаев и всей прочей практики, которые основаны на идее неполноценности или превосходства одного из полов или стереотипности роли мужчин и женщин». Специальный докладчик по вопросу о насилии в отношении женщин в своем докладе о взаимосвязях между культурой и насилием в отношении женщин утверждает, что права человека могут уживаться культурными особенностями и что для этого необходимо бороться с дискриминационными и авторитарными аспектами культуры, сохраняя ее позитивные аспекты. ${ }^{3}$

Особое значение концепция конструктивного релятивизма имеет в связи с ростом числа региональных документов по правам женщин. ${ }^{4}$ Наряду с общими документами по правам человека, где закреплен принцип недискриминации ${ }^{5}$, приняты также ряд специальных документов по правам женщин: Протокол Мапуту о правах женщин в Африке 2003 г. к Африканской хартии прав человека и народов 1981 г. и Межамериканская конвенция о предотвращении, наказании и ликвидации насилия в отношении женщин (Конвенция Белем), которая вступила в силу в 1995 году. В 2011 году Совет Европы принял новую Конвенцию о предупреждении и пресечении насилия в отношении женщин и бытового насилия (Стамбульская конвенция). Значимость региональных документов в том, что они призваны еще более усилить и дополнить универсальную систему прав человека в рамках ООН.

Касательно документов, принятых в рамках региональных организаций, в которых участвует Узбекистан, в рамках СНГ принята Конвенция СНГ о правах и свободах человека 1993г.,

1 Ижиков М. Культурный релятивизм как проблема взаимодействия международного и внутригосударственного права в области защиты прав человека//Вестник Пермского университета,/ 2012 выпуск 1(15) - с.184

${ }^{2}$ Kielsgard M.D. Universal human rights and cultural relativism: a fresh view from the new haven school of Jurisprudence // SSRN.COM: Social Science Research Network. 2011. C. 33 URL: http://www.ssrn.com/abstract=1778124(дата обращения: 09.02.2012).

${ }^{3}$ Report of the Special Rapporteur on violence against women, its causes and consequences, Yakin Ertürk Intersections between culture and violence against women "IMPLEMENTATION OF GENERAL ASSEMBLY RESOLUTION 60/251 OF 15 MARCH 2006 ENTITLED "HUMAN RIGHTS COUNCIL". Доступно на https://documents-dds-ny.un.org/doc/UNDOC/GEN/G07/103/04/PDF/G0710304.pdf?OpenElement

4 Африканская хартия прав человека и прав народов (Банджулская хартия), статья 2 запрещает дискриминацию по любому признаку, включая пол, при пользовании гарантированными Хартией правами. В статье 18 прямо упоминается обязательство африканских государств «заботиться о ликвидации любой дискриминации в отношении женщин и обеспечивать защиту прав всех женщин и детей, как они установлены в международных декларациях и конвенциях»; Устав Организации американских государств содержит положение о недискриминации в главе II (пункт 1 статьи 3), а Американская конвенция о правах человека - в статье 1. Европейская Конвенция о защите прав человека и основных свобод запрещает при осуществлении закрепленных в ней прав дискриминацию по любому признаку, включая пол (статья 14). Региональными политическими организациями, включая Ассоциацию государств Юго-Восточной Азии, Ассоциацию регионального сотрудничества стран Южной Азии, Экономическое сообщество западноафриканских государств и Сообщество по вопросам развития стран юга Африки, также принимались протоколы и резолюции и делались заявления, касающиеся прав человека женщин.

${ }^{5}$ К этим документам относятся Европейская Конвенция о защите прав человека и основных свобод (Рим, 1950 г.) и Европейская Социальная Хартия (пересмотренную) (Страсбург, 1996 г.), Американская декларация прав и обязанностей человека, Американская конвенции по правам человека, Африканская хартия о правах человека и народов. 
но документов, специально посвященных правам женщин, не принято. Определенные усилия принимаются в рамках ОИС, в рамках которого в 2016 году на 6-й сессии конференции министров о роли женщин в развитии стран-участниц ОИС был принят План по продвижению женщин. ${ }^{1}$

Таким образом, на сегодняшний день существует огромный массив международных документов по правам женщин, представляющих собой достаточно солидную правовую основу для эффективного обеспечения прав женщин. Эти документы приняты в различных формах - в форме деклараций, рекомендаций, конвенций и программ или стратегий действий, то есть в форме документов обязательного или рекомендательного характера.

Анализ их содержания позволил выделить наиболее приоритетные направления международно-правового сотрудничества в сфере обеспечения прав женщин, а именно, такие как охрана материнства, обеспечение равенства в семье и сфере труда, защита женщин от насилия.

Bсе больше документов принимается в целях защиты уязвимых слоев женщин, сталкивающихся с множественной дискриминацией. Принятие документов по защите наиболее уязвимых категорий женщин, то есть женщин, подвергающихся множественной дискриминации одна из тенденций в развитии международно-правовых стандартов по правам женщин.

\footnotetext{
${ }^{1}$ Текст документа доступен на https:/www.oic-oci.org/docdown/?docID=2918\&refID=1110
} 